\title{
A COLONIZAÇÃo DA SUSTENTABILIDADE: ANÁLISE DO DISCURSO DE PEÇAS PUBLICITÁRIAS DA NATURA COSMÉTICOS
}

\author{
Andreina Del Carmen Camero de Lima \\ Doutoranda em Administração \\ Universidade Federal de Lavras Lavras - MG - Brasil \\ andreinalima@yahoo.com.br \\ Eliza Pinto Narciso Saltarelli \\ Doutoranda em Administração \\ Universidade Federal de Lavras Lavras - MG - Brasil \\ eliza_narciso@hotmail.com \\ Sabrina Soares da Silva \\ Doutora em Administração \\ Universidade Federal de Lavras Lavras - MG - Brasil \\ sabrinasosil@yahoo.com.br
}

\begin{abstract}
RESUMO
$\mathrm{O}$ conceito de sustentabilidade ganhou destaque no ambiente corporativo nos últimos anos, o que não significa necessariamente que as empresas assumam todos os seus fundamentos. $O$ discurso de sustentabilidade, sendo cooptado pelo capitalismo, torna-se uma ferramenta de marketing. A cooptação de pensamentos alternativos pelo capitalismo, como a sustentabilidade, é mantida pela colonialidade, por meio de discursos hegemônicos que reproduzem e reforçam estruturas institucionais, políticas, econômicas, culturais e de poder. Nesse contexto, este trabalho tem como objetivo analisar o discurso de sustentabilidade em peças publicitárias da Natura Cosméticos a partir das quatro dimensões da colonialidade. As análises evidenciam que os enunciados pretendem destacar características e valores, de modo a persuadir o consumidor a comprar e utilizar os produtos da marca. Ocorre o silenciamento de alguns aspectos, tais como a exploração da natureza, a mercantilização de recursos naturais, os impactos ambientais do extrativismo, e as exigências de padrões de beleza, os quais podem ser relacionados às quatro dimensões da colonialidade.
\end{abstract}

Palavras-chave: Análise do discurso. Colonialidade. Decolonial. Natura. Sustentabilidade.

\section{THE COLONIZATION OF SUSTAINABILITY: A DISCOURSE ANALYSIS OF NATURA COSMÉTICOS'ADVERTISEMENTS}

\begin{abstract}
The concept of sustainability has come prominent in the corporate environment in recent years, which does not necessarily mean companies are assuming all its ground rules. The discourse of sustainability being coopted by capitalism becomes a marketing tool. The cooptation of alternative thoughts by capitalism, such as sustainability, is maintained by coloniality, through hegemonic discourses that reproduce and reinforce institutional, political, economic, cultural, and power structures. In this context, this paper aims to analyze the discourse of sustainability in Natura Cosméticos' advertisements through the four dimensions of coloniality. The analyses show that the advertisements aim to highlight characteristics and values in order to persuade the consumer to buy and use Natura products. There is the silencing of aspects such as the exploration of nature, the mercantilization of natural resources, the environmental impacts of extractivism, and the demands of beauty standards, which may be related to the four dimensions of coloniality.
\end{abstract}

Key words: Coloniality. Decolonial. Discourse analysis. Natura. Sustainability.

Data da submissão: 19/07/2019

Data de aceite: $18 / 12 / 2019$

Revista de Gestão Social e Ambiental - RGSA, São Paulo, v. 14, n. 1, p. 18-37, jan./abr. 2020. 


\section{INTRODUÇÃO}

Nas últimas décadas, houve o agravamento de problemas ambientais e sociais (Hernandez \& Rabinovici, 2015) decorrentes das atividades empresariais. Devido a essas condições, aumentam também as pressões e cobranças por parte da sociedade, especialmente em relação às organizações e sua responsabilização por tais problemas (Coelho, Coelho \& Godoi, 2013).

Diante deste contexto, surge o conceito de sustentabilidade no âmbito corporativo, onde as empresas, por meio de discursos e práticas, tentam modificar seus modelos de gestão com base no tripé da sustentabilidade, abrangendo não apenas a questão econômica, mas também os níveis sociais e ambientais (Hernandez \& Rabinovici, 2015).

Entretanto, a adoção do conceito de sustentabilidade, por parte das empresas, não significa necessariamente assumir todos os seus fundamentos sociais, econômicos e ambientais (Coelho \& Godoi, 2010). Destarte, pode-se considerar que ocorre uma domesticação da sustentabilidade, em que não se questionam os padrões empresariais e se busca apenas uma adaptação superficial da lógica capitalista de exploração dos recursos naturais aos anseios da sociedade (Pires \& Fischer, 2014).

O discurso de sustentabilidade acaba sendo cooptado pela visão dominante de mundo (capitalismo) e torna-se apenas mais uma ferramenta de marketing, mantendo-se a visão antropocêntrica sobre a natureza como fonte de recursos inesgotáveis e que acumula infinitamente os resquícios da ação humana (Coelho, Coelho \& Godoi, 2013; Silva, Reis \& Amâncio, 2011).

Essa visão antropocêntrica e pautada na lógica da modernidade estimula a perpetuação do sistema capitalista, por meio da apropriação da terra, da exploração dos recursos naturais e da reprodução de diversas formas de dominação entre grupos dominantes e as classes mais vulneráveis e subalternizadas da sociedade (Anderson, 2014).

Para Quijano, estas formas de dominação podem ser denominadas como colonialidade. Para o autor, as bases de poder e subordinação continuam a ser perpetuadas no mundo atual por meio de "[...] mecanismos do sistema-mundo capitalista colonial-moderno" (Assis, 2014, p. 614; Bernardino-Costa \& Grosfoguel, 2016). Ou seja, a sociedade moderna e as lógicas subjacentes a ela, como a exploração exacerbada da natureza e cooptação de pensamentos alternativos (como a sustentabilidade) pelo capitalismo, são mantidas pela colonialidade em suas quatro dimensões: do poder, do ser, do saber e da natureza (Oliveira, 2016).

A disseminação das formas de colonialidade se dá por diversos meios, mas especialmente por meio de discursos hegemônicos (capitalistas) que reproduzem e reforçam estruturas institucionais, políticas, econômicas, culturais e de poder (Ugarte, 2014). No âmbito específico da sustentabilidade, tais discursos impõem a necessidade de sempre atender a demanda crescente por recursos e matérias-primas, desconsiderando ou minimizando os impactos que destroçam o equilíbrio ambiental e modificam as relações socioeconômicas (Araújo \& Fernandes, 2016).

Silva, Reis e Amâncio (2014, p. 91) destacam que a sustentabilidade encontra-se presente nos vários discursos organizacionais, tentando "[...]justificar os impactos das diferentes atividades produtivas sobre o ambiente e legitimar sua atuação frente à sociedade". Esses discursos de sustentabilidade são propagados "[...]nas falas, documentos, folders, jornais, avisos e comunicações [...]", sendo uma das principais estratégias discursivas organizacionais (Coelho \& Godoi, 2010, p. 72).

Segundo Coelho, Coelho e Godoi (2013, p. 175), estudar os discursos de sustentabilidade pode ajudar a ter uma compreensão mais ampla sobre a realidade organizacional, “[...] evidenciando grupos de interesse, conflitos e relações de poder, [...] em um contexto dominado por interesses econômicos". Deste modo, optou-se por utilizar a Análise do Discurso Francesa, como perspectiva teórico-metodológica neste trabalho, para o estudo dos discursos de sustentabilidade, pois entende o discurso como qualquer prática pelo qual os sujeitos dão sentido à realidade, além de considerar que quaisquer práticas sociais podem ser analisadas discursivamente (Ruiz Ruiz, 2009). A Análise do 
Andreina Del Carmen Camero de Lima, Eliza Pinto Narciso Saltarelli, Sabrina Soares da Silva

Discurso propõe a compreensão de um plano discursivo que articula linguagem e sociedade (Rocha \& Deusdará, 2005).

Considerando a discussão apresentada, este trabalho tem como objetivo analisar o discurso de sustentabilidade utilizado em peças publicitárias da Natura Cosméticos a partir das quatro dimensões da colonialidade. Para atender ao objetivo proposto, o trabalho é composto pelas seguintes seções: introdução; fundamentação teórica baseada nas discussões de colonialidade, sustentabilidade e análise do discurso francesa; metodologia; análises e discussão dos resultados; e por fim, pelas considerações finais e referências.

\section{FUNDAMENTAÇÃO TEÓRICA}

Neste tópico, serão apresentados os fundamentos teóricos sobre o Pensamento Decolonial, Sustentabilidade e Análise do Discurso Francesa. A base teórica aqui apresentada pretende embasar as análises e discussões do trabalho.

\subsection{Pensamento decolonial: a colonialidade do poder, do ser, do saber e da natureza}

O pensamento decolonial surgiu no fim dos anos 90, com a criação do grupo designado Modernidade/Colonialidade (M/C) (Carvalho, 2015), em que o conceito de decolonial assume a concepção de crítica ao pensamento moderno europeu (Bernardino-Costa \& Grosfoguel, 2016). O grupo constituído por diversos autores tem por objetivo radicalizar os argumentos pós-coloniais na América Latina, por meio de uma "[...]renovação crítica para as ciências sociais do continente e [que] defende a perspectiva decolonial como uma opção epistêmica, teórica e política para que se compreenda e atue em um mundo marcado pela colonialidade" (Espanhol, 2017, p. 1; Mignolo, 2007).

Quijano e Wallerstein (1992) apontam que a condição colonial deixa resquícios históricos que não se apagam após a independência, resistindo por meio de uma hierarquia sociocultural baseada no eurocentrismo, em que as estruturas política, econômica e cultural mantêm as relações de poder e dominação, constituindo-se assim na marca mais profunda deixada pela modernidade. Nesse sentido, o grupo $\mathrm{M} / \mathrm{C}$ propõe uma nova visão sobre a modernidade, considerando que modernidade e colonialidade são acontecimentos mutuamente dependentes e constitutivos (Espanhol, 2017).

O pensamento decolonial é pautado em uma visão crítica a qual é capaz de ampliar a compreensão acerca das relações de poder construídas a partir da subalternização de determinados povos, relações essas que impulsionaram um modelo global de acumulação (e de poder) durante a colonização e que perdura até os dias atuais (Merino Acuña, 2015). Esse modelo de acumulação perpetua-se por meio de sistemas institucionais, legais, econômicos e políticos (Ashar, 2015; Merino Acuña, 2015; Ugarte, 2014).

O modelo de acumulação a que se referem os autores acima é o capitalismo. Merino Acuña (2015) afirma que o capitalismo, geralmente, é visto de forma desvinculada do colonialismo, porém o desenvolvimento do capitalismo como um sistema econômico global só ocorre a partir do "descobrimento" da América, quando se constitui, então, o sistema mundo moderno/colonial. Deste modo, a colonização é um elemento essencial ao capitalismo, o qual se desenvolveu principalmente a partir dos processos de desapropriação e exploração a que foram submetidos os territórios coloniais (Ballestrin, 2017; Carvalho, 2015; Merino Acuña, 2015).

A abordagem decolonial busca abordar essas conexões entre modernidade e colonialidade que estruturam o capitalismo, pois o contexto mundial presente foi configurado com base no processo de expansão e domínio global do capitalismo liberal, cujas raízes estão no projeto da modernidade (Merino Acuña, 2015). Assim, é por meio dos vínculos entre capitalismo e colonialismo e as relações de poder estabelecidas pela modernidade europeia que se pode explicar a ordem mundial atual. 
Atualmente, as nações ex-colônias têm experimentado um processo que pode ser entendido como "recolonização" ou "colonialismo global", em que formas históricas da época colonial, (como a exploração de recursos naturais e a conquista territorial), ressurgem com novos rótulos, estratégias e discursos, mas continuam a reproduzir as lógicas coloniais, mantendo os interesses políticos e econômicos de grupos dominantes, como as corporações (Ballestrin, 2015). Esse processo, que extrapola as especificidades do colonialismo histórico, Quijano denomina como colonialidade, que é reproduzida a partir das dimensões do poder (Quijano, 2000), do saber, do ser (Mignolo, 2011; Ballestrin, 2017) e da natureza (Escobar, 2005).

Os processos de recolonização e colonialismo interno que têm ocorrido na América Latina baseiam-se na exploração de mão de obra barata existente nas regiões periféricas e, pelo controle e pela exploração de recursos naturais. Em razão da colonialidade do poder, esse modelo políticoeconômico se estabelece como um padrão hegemônico de acumulação de capital instituído nos países periféricos, reproduzindo um processo desigual de acesso e domínio dos recursos naturais e dos territórios, reforçando a lógica de acúmulo, concentração e espólio de capital (Coradin, 2017).

Nas dimensões do ser e do saber, o controle do conhecimento e da subjetividade relaciona-se à importação e imposição da cultura europeia, incluindo a sua linguagem e seu conhecimento, sobre os povos coloniais. Esse processo atinge uma dominação colonial total, em que simplifica e nega culturas, saberes e sociedades previamente estabelecidas, impondo a ideia de forte crença no desenvolvimento e progresso (Anderson, 2014), submetendo populações locais a um processo de subalternização (Carvalho, 2012).

Em relação à apropriação da terra e a exploração de trabalho, Assis (2014) argumenta que há um posicionamento utilitarista em relação à exploração das riquezas naturais, o que ele denomina como colonialidade na apropriação da natureza. $\mathrm{O}$ autor considera que essa colonialidade refere-se aos modos hegemônicos de concepção e extração de recursos naturais como mercadorias, aniquilando outros modos de convívio com o meio ambiente (Assis, 2014). Na visão hegemônica de modernidade, a exploração capitalista da natureza se converte em vantagem econômica que alimenta a lógica de acumulação de capital, bem como sustenta o funcionamento do sistema mundo moderno-colonial (Assis, 2008, 2014.).

\subsection{Sustentabilidade no contexto organizacional}

Com o aumento e agravamento de problemas em relação às condições ambientais, tais como o aquecimento global e a escassez e esgotamento de recursos naturais (Hernandez \& Rabinovici, 2015), são acirradas as pressões e cobranças por parte da sociedade, especialmente em relação às práticas corporativas ante esses problemas (Coelho, Coelho \& Godoi, 2013). Assim, as empresas estão se tornando cada vez mais conscientes do imperativo da sustentabilidade e da proteção ambiental (Carrieri, 2003; Hays et al., 2020). Diante disso, as organizações passam a assumir estratégias que demonstrem um engajamento com posicionamentos que expressem preocupação social e ambiental, buscando a sua legitimação perante a sociedade, bem como a manutenção e perpetuação da atividade organizacional (Coelho, Coelho \& Godoi, 2013).

O reconhecimento de que os recursos naturais não são inesgotáveis e que a ação do homem sobre o ambiente tem consequências irreversíveis, fez com que diversas empresas adotassem de fato medidas socioambientais e sustentáveis a partir dos anos 1980, tentando superar a visão de incompatibilidade entre desenvolvimento e preservação ambiental. Nesse contexto, as empresas adotam em seus discursos e práticas o conceito de sustentabilidade corporativa, levando "[...]à modificação dos modelos de gestão para além do econômico, adentrando os planos sociais e ambientais, ou seja, o tripé da sustentabilidade" (Hernandez \& Rabinovici, 2015, p. 38).

Segundo Silva, Reis e Amâncio (2014), a sustentabilidade é um conceito que tem sido largamente discutido em vários campos de estudos, mas ainda assim não houve a consolidação de uma definição única. Essa falta de consenso sobre o significado atribuído à sustentabilidade pode levar ao uso indiscriminado e acrítico do termo, resultando em uma situação de reprodução e 
continuidade de um modelo antropocêntrico e antiecológico de domínio e exploração da natureza (Cabette, 2007). Nesse sentido, é preciso fazer uma delimitação sobre o conceito de sustentabilidade.

Redclift (1994) e Becker (1997) apontam que a origem etimológica de sustentabilidade é derivada do verbo sustentar, com sentido similar ao verbo manter. A categoria sustentabilidade, proveniente da biologia e da ecologia, significa a capacidade de um ecossistema se manter em um equilíbrio dinâmico que permita a subsistência da biodiversidade e incluindo a todos (Boff, 2010). Para Amazonas (2002), a discussão acerca da sustentabilidade deve ser pautada por dois aspectos: as razões da sustentabilidade, (decorrentes de questões éticas) e as condições para a sustentabilidade, que estimulam diversos conceitos e critérios para a realização da sustentabilidade.

Corroborando com as discussões, Cavalcanti (1998, p. 165) traz a seguinte a definição:

[...]sustentabilidade significa a possibilidade de se obterem continuamente condições iguais ou superiores de vida para um grupo de pessoas e seus sucessores em dado ecossistema. Numa situação sustentável, o meio ambiente é menos perceptivelmente degradado, embora, como saibamos, o processo entrópico nunca cesse, procedendo invisível e irrevogavelmente levando ao declínio inflexível do estoque de energia disponível na terra. [...] O conceito de sustentabilidade equivale à ideia de manutenção de nosso sistema de suporte da vida. Ele significa comportamento que procura obedecer às leis da natureza. Basicamente, trata-se do reconhecimento do que é biofisicamente possível em uma perspectiva de longo prazo.

Embora o conceito de sustentabilidade, como apresentado por Cavalcanti (1998), devesse enfatizar o respeito às condições biofísicas da natureza, Redclift (2005) relata que as discussões envolvendo a sustentabilidade como um processo político deslocaram seu foco das necessidades humanas, para os direitos, tanto humanos quanto não-humanos. $\mathrm{O}$ discurso da sustentabilidade passou a envolver outros conceitos discutidos nas ciências sociais, como o poder, a distribuição e a igualdade (Barnett, 2001; Martinez-Alier, 1992; Mason, 1999; Redclift, 2005). Dessa forma, as preocupações sobre as relações entre ambiente, justiça social e governança se tornaram vagos nos discursos, principalmente quando conjugados ao desenvolvimento sustentável, tornando obscuros os relacionamentos estruturais entre poder, consciência e ambiente. Na busca por uma visão mais inclusiva sobre sustentabilidade, a retórica política se focou, com grande frequência, em discursos envolvendo questões ambientais (Redclift, 2005).

O uso de definições vagas sobre o conceito de sustentabilidade acabou por torná-lo atrativo, pois permitia uma tradução direta de vários objetivos políticos em um conceito amplamente aceito. Esse aspecto acarreta duas desvantagens: primeiramente, o conceito pode ser usado de modo abusivo com finalidade ideológica e de defesa de interesses econômicos, que se afastam das ideias originais propostas pela sustentabilidade; e por último, impede uma análise objetiva ou neutra do conceito, que é a dificuldade básica na busca de uma perspectiva científica da sustentabilidade (Silva, 2011).

Atualmente, a noção de sustentabilidade tem sido amplamente atrelada à de desenvolvimento, mesmo quando o termo sustentável não está explícito, como exemplifica Sachs (2005, p. 10) com a afirmativa de que o desenvolvimento "[...]não pode se limitar unicamente aos aspectos sociais e sua base econômica, ignorando as relações complexas entre o porvir das sociedades humanas e a evolução da biosfera". Nesse interím, Lins e Silva (2009) destacam que os índices que buscam avaliar a sustentabilidade empresarial geralmente se baseiam no conceito do Triple Botton Line, que conjuga as dimenões econômico-financeiras, sociais e ambientais.

Mas, é preciso destacar que a sustentabilidade não deve ser atrelada apenas à questão do desenvolvimento, pois como o mesmo autor afirma, a sustentabilidade é um "[...] que envolve um processo de mudança, contempla dimensões - social; cultural; ecológica; ambiental; territorial; econômica; política (nacional e internacional)[...]", as quais podem ser refletidas de forma individual ou coletiva (Sachs, 2004, p.85).

Hoffman (1999) descreve que esse processo de mudança da sustentabilidade teve seu início na década de 1960 com uma sucessiva redefinição de práticas ambientais no contexto corporativo 
dos EUA, especialmente nas indústrias de alto impacto ambiental. Ao longo das décadas seguintes, observam-se diversas mudanças estruturais, técnicas e culturais no comportamento corporativo ao redor do mundo, como o controle da poluição e a minimização de resíduos.

Por outro lado, Coelho, Coelho e Godoi (2013) acreditam que a sustentabilidade foi elaborada justamente para substituir o conceito de desenvolvimento econômico, sendo difundida pelos países capitalistas diante das limitações reveladas pelo discurso desenvolvimentista no contexto de crise vivido durante a Guerra Fria.

Estudos da abordagem crítica da administração sugerem que o discurso de sustentabilidade foi integrado à realidade organizacional, dada a sua necessidade para a manutenção dos negócios (Pires \& Fischer, 2014). Barbieri (2007) e Carrieri (2003) esclarecem que as questões ambientais se tornaram importantes para a competitividade das organizações e assim alguns fatores, tais como abertura comercial, pressão de investidores e a minimização de riscos, também incentivaram um maior comprometimento das organizações com o ambiente. Porém, associar sustentabilidade e organização é uma tarefa complexa (Silva, Reis \& Amâncio, 2014), pois não haveria como uma organização ser, de fato, sustentável, uma vez que sua adoção efetiva poderia até mesmo trazer o questionamento da finalidade das empresas em si (Pires \& Fischer, 2014).

É inegável que os investimentos socioambientais se tornaram mais atrativos para as organizações nos últimos anos, à medida que estudos passaram a indicar sua contribuição na promoção da empresa e no incremento de seus resultados financeiros. Porém, mesmo havendo o reconhecimento da necessidade de uma gestão organizacional voltada para a sustentabilidade, o nível e o modo como as ações serão implementadas varia em cada organização conforme a natureza de suas atividades. Ou seja, as formas como a organização assume seus compromissos com o meio ambiente podem variar imensamente (Barbieri, 2007), pois a política corporativa adotada dependerá das circunstâncias enfrentadas pela empresa e suas estratégias de negócios (Reinhardt, 1999), além de seus valores e princípios (Figueiredo, Abreu \& Las Casas, 2009).

Porém, é importante compreender que, no contexto atual, os problemas ambientais não devem ser vistos apenas como "[...] produto de uma relação entre homem e natureza, mas se situar no campo das relações que os diferentes grupos estabelecem no espaço social, bem como as estratégias que se elaboram no embate pela apropriação, controle e uso dos recursos naturais" (Carrieri, 2003, p. 1211).

Nesse sentido, muitas vezes a adoção do conceito de sustentabilidade nas organizações não passaria de uma intervenção político-narrativa, em que o objetivo é "[...]minimizar ou buscar soluções aos problemas inerentes às contradições e limitações do modelo de desenvolvimento atualmente posto na sociedade[...]", de modo a garantir a manutenção e perpetuação do modelo capitalista, buscando 'alternativas' para as consequências da deterioração ambiental (Coelho, Coelho \& Godoi, 2013, p. 157).

Para Carrieri (2003, p. 1212), é possível observar diferentes modos de cooptação do discurso ecológico, principalmente por meio da incorporação de alguns termos, tais como degradação, índices de poluição, tratamento de resíduos, etc., aos discursos organizacionais, porém, sem “[...] incorporar-se as concepções que esses termos trazem dos discursos ecológicos, de questionamento do modo de produção. Ou seja, os signos/símbolos são reproduzidos nos discursos organizacionais, mas lhes são dados novos significados". Esteva (1999) e Langhelle (2000) complementam que, frequentemente, os discursos sobre sustentabilidade utilizam práticas de comunicação carregadas de significados simbólicos e políticos, como "poder democrático" e "justiça natural", o que pode obscurecer seu real sentido.

A partir de uma perspectiva crítica, Pires e Fischer (2014) apresentam a noção de "sustentabilidade domesticada". Este termo remete ao modo como o conceito de sustentabilidade tem sido utilizado pelas empresas, adotando uma postura que não traz questionamentos profundos em relação aos padrões empresariais e simplesmente assume uma atuação combinada ao modelo de sistema social dominante em vigor. Ou seja, trata-se somente de uma "[...]nova adaptação reativa e, 
Andreina Del Carmen Camero de Lima, Eliza Pinto Narciso Saltarelli, Sabrina Soares da Silva

muitas vezes, cosmética da empresa a uma demanda social emergente" (Pires \& Fischer, 2014, p. 56).

Silva, Reis e Amâncio (2011) destacam que o paradigma da sustentabilidade poderia representar uma superação da visão antropocêntrica dominante, onde a natureza é percebida apenas como fonte de recursos inesgotáveis e que acumula infinitamente os resquícios da ação humana, para atender às demandas de consumo da sociedade. Mas, embora a incorporação da sustentabilidade às estratégias e às práticas organizacionais proporcionem muitos benefícios sociais e ambientais, isso não é suficiente para garantir que as organizações sejam sustentáveis, pois a sustentabilidade envolve mudanças mais profundas e de posicionamento das corporações (Barbieri, 2007).

Coelho, Coelho e Godoi (2013, p. 175) destacam que diversos estudos têm demonstrado a adoção do discurso de sustentabilidade como uma ferramenta de marketing, de modo falacioso e banalizado, "[...]construído e constantemente reconstruído num contexto dominado por interesses econômicos".

Muitas vezes, as "[...] empresas parecem estar mais preocupadas em passar uma imagem de empresa preocupada com aspectos socioambientais do que efetivamente o são[...]", porque a forma "[...] como a sociedade percebe as empresas tornou-se um fator relevante nas decisões estratégicas" (Lins \& Silva, 2009, p. 96).

Deste modo, torna-se claro que o marketing tem uma função essencial para a construção da imagem das empresas, levando aos consumidores mensagens que transmitam uma relação genuína entre a empresa e os diversos tipos de ações ambientais, tentando evitar a percepção de possíveis atuações ambientais superficiais, voltadas apenas para campanhas de publicidade (Figueiredo, Abreu \& Las Casas, 2009).

A sustentabilidade tornou-se instrumento de visibilidade corporativa, estando frequentemente presente nas peças publicitárias, com foco no aumento de consumidores e do lucro (Santos, 2014). Conclui-se, portanto, que os novos discursos envolvendo a sustentabilidade usam uma nova roupagem, mas ocultam, ou marginalizam, as iniquidades e as distinções culturais que deveriam governar a agenda ambiental internacional (Redclift, 2005).

Ante a discussão apresentada, é possível perceber que o discurso de sustentabilidade tem sido perpassado por conflitos de interesse e relações de poder que constituem o âmbito organizacional, os quais precisam ser avaliados quanto a sua efetividade na construção de um mundo "[...]socialmente equitativo, ambientalmente equilibrado e economicamente eficiente e produtivo" (Coelho, Coelho \& Godoi, 2013, p. 153).

\subsection{Análise do discurso}

Para Orlandi (2005), a palavra discurso, remete à ideia de percurso em um sentido de movimento, sendo a palavra em movimento e prática de linguagem. Baptista e Silva (2015) afirmam que a relação entre a linguagem e a realidade não é transparente e que a análise do discurso busca conhecer o sentido oculto presente no discurso.

Ruiz Ruiz (2009) explana que, do ponto de vista sociológico, pode-se definir discurso como qualquer prática pelo qual os sujeitos dão sentido à realidade. Nestes termos, o discurso apresenta uma diversidade de formas muito ampla, onde quaisquer práticas sociais podem ser analisadas discursivamente.

A análise do discurso surgiu a partir da década de 1960, na França, como uma disciplina que corresponde a uma visão sobre análise de textos, sob uma perspectiva da linguística e de outras áreas das ciências humanas e sociais, com o propósito de superar as insuficiências de análises conteudistas e compreender a linguagem a partir do funcionamento social da língua, trabalhando com o sentido e não apenas com o conteúdo do texto em torno dos sentidos produzidos a partir dele (Rocha \& Deusdará, 2005; Chizzotti, 2010; Baptista\& Silva, 2015). 
Assim, a Análise do Discurso propõe o entendimento de um plano discursivo que articula linguagem e sociedade (Rocha \& Deusdará, 2005) e que o discurso não se limita a uma estrutura ordenada de palavras, nem a uma descrição ou a um meio de comunicação, tampouco se reduz a mera expressão verbal do mundo (Chizzotti, 2010). Portanto, a Análise do Discurso se interessa por estudar a língua funcionando para a produção de sentidos (Silva, 2005) e caracteriza-se como uma abordagem teórico-metodológica.

Cabe ressaltar que existem diferentes linhas de análise do discurso. Segundo Gonçalves (2016) existem muitos estilos diferentes, com enfoques variados, tendo como base diversas tradições teóricas, que têm em comum considerar o discurso como objeto e rejeitam a noção de que a linguagem é simplesmente um meio neutro de refletir, ou descrever o mundo, além da convicção da importância central do discurso na construção da vida social. Dentre as variáveis existentes, este autor aponta a Análise do Discurso Francesa, que privilegia a história e os textos advindos de instâncias institucionais.

Um dos principais autores da vertente Francesa é Michel Pêcheux, um filósofo francês que, fundamentado na teoria marxista de Louis Althusser, propõe uma análise linguística baseada em uma teoria materialista do discurso (Baptista \& Silva, 2015) dividida entre a descrição linguística e a dificuldade em responder às exigências interpretativas das ciências humanas (Gonçalves, 2016).

As contribuições do trabalho de Pêcheux se concentram em considerar o momento linguístico, filosófico, histórico e computacional, além da forte influência dos trabalhos de Althusser sobre ideologia e aparelhos ideológicos do Estado e os esforços para voltar a epistemologia e a história das ciências para o domínio das ciências humanas de onde deriva a proposta pecheutiana da teoria materialista do discurso (Baptista \& Silva, 2015).

Fairclough (2001) acrescenta que, ao categorizar o panorama dos principais estudos em Análise do Discurso, Pêcheux contribuiu para uma abordagem crítica de análise do discurso ao "[...]tentar combinar uma teoria social do discurso com um método de análise textual" (Fairclough, 2001, p. 51). Segundo Mussalim (2018), a Análise do Discurso de vertente francesa tem se inclinado ao estudo sobre "[...]a problemática dos discursos, enunciados e sentidos produzidos numa espacialidade e/ou temporalidade anterior à produção de um discurso em questão" (p. 402).

A Análise do Discurso Francesa tem como uma de suas pressuposições básicas que o discurso há de ser pensado nas suas condições de produção e deve estabelecer um diálogo essencial entre discurso e exterioridade, a qual é considerada como silenciosa por dois motivos: "(1) dissolvese na invisibilidade do não-dito ou porque (2) confunde-se na balbúrdia do já-dito" (Villarta-Neder, 2004, p.134). Além disso, o autor ainda expõe duas tipificações sobre essas relações entre silêncio e o movimento dos sentidos citadas anteriormente:

(1) Um excesso do dizer, sob a forma de uma necessidade de reafirmar um sentido pode ser interpretado como um silenciamento de um espaço polissêmico que emerge e incomoda o sujeito, obrigando-o a tentar evitar outros sentidos. E a existência de marcas que indiquem um abandono da tentativa de estabelecer um sentido apontaria (2) um silêncio (não-dizer) sobre esses sentidos escorregadios e/ou inconvenientes (Villarta-Neder,2004, p.134).

Sobre a concepção de sujeito, Mussalim (2001) afirma que não pode ser considerado como "indivíduo que fala ("eu falo"), como fonte do próprio discurso", é considerado como assujeitado à máquina, pois está submetido a regras específicas que demarcam o discurso que enunciam, ou seja, seria a ideologia, ou uma teoria ou a própria instituição que de fato fala.

A Análise do Discurso Francesa entende que o sujeito representa as condições de produção do discurso de uma maneira imaginária, visto que não possui acesso e nem conhecimento das reais condições de produção do seu discurso devido à questão da própria inconsciência de que é atravessado. Nota-se que esse conceito de inconsciência relaciona-se ao conceito de discurso trabalhado pela Análise do Discurso (Pinto, Lima, Lobato, \&Villarta-Neder, 2014). Pêcheux (1969) denomina essa relação imaginária de jogos de imagem de um discurso, conforme apresentado figura 1 , do próprio autor. 
Andreina Del Carmen Camero de Lima, Eliza Pinto Narciso Saltarelli, Sabrina Soares da Silva

\begin{tabular}{|c|c|c|c|}
\hline \multicolumn{2}{|c|}{$\begin{array}{l}\text { Expressão que designa as } \\
\text { formações imaginárias }\end{array}$} & Significado da expressão & $\begin{array}{l}\text { Questão implícita cuja "resposta" } \\
\text { subentende a formação imaginária } \\
\text { correspondente }\end{array}$ \\
\hline \multirow[t]{2}{*}{ A } & \multirow{2}{*}{$\begin{array}{l}\text { IA (A) } \\
\text { IA (B) }\end{array}$} & $\begin{array}{c}\text { Imagem do lugar de A para o } \\
\text { sujeito colocado em A }\end{array}$ & "Quem sou eu para lhe falar assim?" \\
\hline & & $\begin{array}{l}\text { Imagem do lugar de B para o } \\
\text { sujeito colocado em A }\end{array}$ & $\begin{array}{c}\text { "Quem ele é para que ele me fale } \\
\text { assim?" }\end{array}$ \\
\hline \multirow[t]{2}{*}{ B } & \multirow{2}{*}{$\begin{array}{l}\text { Ів (B) } \\
\text { Ів (A) }\end{array}$} & $\begin{array}{l}\text { Imagem do lugar de B para o } \\
\text { sujeito colocado em B }\end{array}$ & $\begin{array}{c}\text { "Quem sou eu para que ele me fale } \\
\text { assim?" }\end{array}$ \\
\hline & & $\begin{array}{l}\text { Imagem do lugar de A para o } \\
\text { sujeito colocado em B }\end{array}$ & "Quem é ele para que me fale assim?" \\
\hline $\bar{A}$ & IA (R) & "Ponto de vista de A sobre R" & "De que lhe falo assim?" \\
\hline $\mathrm{B}$ & IB $(\mathrm{R})$ & "Ponto de vista de B sobre R" & "De que ele me fala assim?" \\
\hline
\end{tabular}

Figura 1: Jogos de Imagem

Fonte: Pêcheux $(1969,1990)$

Pêcheux (1990, p.79-87) afirma que o discurso não é uma simples transmissão de informações, deve ser entendido como "efeitos de sentido" entre A e B. Estes são lugares determinados dentro da estrutura de uma formação social e representados pelas formações imaginárias, ou seja, a imagem que o Sujeito $\mathrm{A}$ tem de si, a imagem que tem do ouvinte $\mathrm{B}$, a imagem que o ouvinte B tem do sujeito A, e assim por diante.

Para analisar essas imagens deve-se incluir o contexto, as situações/situação em que o discurso aparece, visto que ele é um objeto imaginário, não seria a realidade física. Para Pêcheux (1990, p.82), “[...]existem nos mecanismos de qualquer formação social regras de projeção que estabelecem as relações entre as situações (objetivamente definíveis) e as posições (representaçõ es dessas situações)". Portanto, as formações imaginárias são responsáveis pelas "antecipações das representações" que são meio para a construção das estratégicas discursivas, ou seja, elas fazem parte das condições de produção do discurso. Trabalha-se com os sentidos enquanto efeitos que se fazem possíveis a partir de dadas condições de produção (Leite, 2017).

Entre as estratégias discursivas mais comuns para construção de representações no contexto empresarial estão as peças publicitárias. De acordo com Silva, Simonian e Filho (2013), a publicidade é orientada pelo processo de produção de valores e signos que são balizados por produtos do cotidiano, em áreas diversas, tais como lazer, saúde, moradia, etc. Assim, a publicidade utiliza-se da arte, do imaginário e do senso comum para construir suas ideias, inserindo "[...]os serviços e produtos divulgados em uma atmosfera idílica, em um mundo de 'perfeição' onde há a hiper valorização da beleza, da alegria, da diversão, da felicidade”. E justamente por tais motivos, "[...]a publicidade é frequentemente criticada pelo fato de as problemáticas de suas mensagens recorrerem invariavelmente ao mito da abundância material e ao fato de uma pessoa existir a partir do uso/compra de produtos e serviços" (Silva, Simonian \& Filho, 2013, p. 4-5).

Portanto, neste trabalho optou-se por analisar as representações construídas sobre sustentabilidade em peças publicitárias da Natura Cosméticos, por meio do primeiro jogo de imagens que aparece da figura 1: IA(A): Imagem do lugar de A para o sujeito colocado em A: "Quem sou eu para que eu lhe fale assim?" Para tanto, serão apresentados a seguir os passos metodológicos do estudo.

\section{METODOLOGIA}

Esta pesquisa caracteriza-se como qualitativa e possui caráter descritivo, ou seja, busca conhecer quais aspectos são utilizados no discurso de peças publicitárias de uma campanha da Natura para criar uma imagem voltada a sustentabilidade. Para a construção da análise, tendo como base a abordagem teórico-metodológica da Análise do Discurso francesa, o corpus da pesquisa foi

Revista de Gestão Social e Ambiental - RGSA, São Paulo, v. 14, n. 1, p. 18-37, jan./abr. 2020. 
constituído de peças publicitárias disponíveis na conta oficial da Natura Cosméticos na rede social Instagram. Todas as peças publicitárias utilizadas neste trabalho são de acesso público.

O recorte do corpus da pesquisa foi feito a partir da escolha de anúncios publicados por meio de postagens na rede social Instagram. A opção pelo Instagram deu-se por se tratar de uma rede social que permite o compartilhamento de fotos e vídeos entre seus usuários, que somavam um bilhão de pessoas em todo o mundo (Instagram, 2018) no ano de 2018. No Brasil, a rede social conta com 300 milhões de usuários, ficando atrás apenas do Facebook, e por isso, é considerada uma opção de anúncio comparada a mídia de massa (Abemd, 2020). Segundo Silva (2011), as redes sociais são estruturas que permitem a interação e a representação de relacionamentos de modo digital e conectam pessoas que se encontram em locais distintos em um espaço virtual comum gratuito e de livre acesso, que pode ser um perfil em um site de relacionamento, um blog, uma página da internet (Silva, 2011).

A escolha pela empresa Natura Cosméticos justifica-se pela expressividade da empresa em ações de marketing e comerciais que utilizam o tema sustentabilidade e natureza. A empresa pos sui a linha de produtos Ekos, que se apresenta como "Linhas completas de produtos de cuidados diários desenvolvidos com bioativos da Amazônia" (Natura, 2018) e possui a certificação Uebt ${ }^{\mathrm{i}}$, um selo que valoriza a ética nas relações com a natureza e com as pessoas (Natura, 2018). Por estas características, as peças publicitárias desta linha foram selecionadas para comporem o corpus da pesquisa.

Foram selecionadas três postagens que fazem a divulgação de produtos Natura Ekos e os benefícios de seu uso. A escolha das peças para composição do corpus limitou-se a três, devido ao enfoque na linha Natura Ekos e a disponibilidade de peças publicadas na rede social escolhida, considerando o período da seleção pelos autores, realizada em setembro de 2018. As peças publicitárias selecionadas foram publicadas na conta da Natura Cosméticos no Instagram entre os meses de maio e agosto de 2018.

A análise do corpus escolhido pode revelar traços importantes do discurso da empresa e contribuir para o entendimento de como as peças publicitárias utilizam o conceito de sustentabilidade para se comunicar e disseminar um discurso. Apesar de limitado, o corpus foi considerado adequado por conter elementos possíveis de serem analisados e contextualizados segundo a colonialidade, a sustentabilidade e a Análise do Discurso Francesa.

Ao buscar analisar as representações construídas pela Natura Cosméticos sobre sustentabilidade, pelo primeiro jogo de imagens que aparece na figura 1: "IA(A): Imagem do lugar de A para o sujeito colocado em A", pretende-se compreender a imagem que a Natura Cosméticos tenta construir para seus clientes. A seguir, serão apresentadas as peças publicitárias selecionadas e as análises feitas utilizando a AD Francesa aportada pela abordagem da colonialidade do ser, do conhecimento, da natureza e do poder.

\section{ANÁLISES E DISCUSSÃO}

Neste tópico será apresentada uma breve contextualização sobre a empresa Natura Cosméticos, bem como a descrição das peças publicitárias selecionadas para realização do trabalho e, em seguida, as análises e discussões com base nas quatro dimensões da colonialidade.

\subsection{Contextualização sobre a empresa Natura}

A Natura é uma empresa brasileira, fundada em 1969, cuja produção e desenvolvimento de produtos encontram-se centrados no Brasil, com sede principal em Cajamar - São Paulo, apesar de já possuir operações comerciais fora do país. A empresa ocupa papel de destaque no mercado interno de cosméticos e produtos de higiene pessoal, com um portfólio composto por cerca de 600 produtos de maquiagem, perfumaria, tratamentos, entre outros (Vasconcelos \& Vasconcelos, 2003; Alcazar, Spers \& Arida, 2007). 
Um dos pontos diferenciais da Natura está no seu discurso de sustentabilidade, devido às estratégias de responsabilidade ambiental e pelos modos de fabricação dos seus produtos. Tal noção de sustentabilidade forneceria um cosmético ético e atrelado à biodiversidade, sendo a beleza um integrador holístico (Vasconcelos \& Vasconcelos, 2003; Alcazar, Spers \& Arida, 2007).

Segundo informações apresentadas no Relatório Anual de 2017 da Natura, disponível no website oficial da empresa, a razão de ser (ou missão) da Natura é criar e comercializar produtos e serviços que promovam o bem-estar/estar bem. Dentre os valores divulgados, destaca-se: a busca permanente do aperfeiçoamento para promover o desenvolvimento dos indivíduos, das organizações e da sociedade, a busca da beleza liberta de preconceitos e manipulações, e o desenvolvimento sustentável da sociedade.

Quanto à sua visão, apresenta-se a seguinte declaração: A Natura, por seu comportamento empresarial, pela qualidade das relações que estabelece e por seus produtos e serviços, será uma marca de expressão mundial, identificada com a comunidade das pessoas que se compromete com a construção de um mundo melhor por meio da melhor relação consigo mesmas, com o outro, com a natureza da qual fazem parte, com o todo.

Este estudo optou por enfocar a linha Ekos. A proposta desta linha de produtos está na combinação de conhecimentos populares e científicos, sendo produzida com base em matériasprimas oriundas da biodiversidade brasileira, coletadas por meio de atividades extrativistas de comunidades localizadas principalmente na região amazônica (Alcazar, Spers \& Arida, 2007; Clemente \& Melo, 2015; Natura, 2018). A escolha pela linha e pelas peças publicitárias que tratam especificamente destes produtos, se deu por ser este o segmento da empresa com maior apelo às questões de sustentabilidade, natureza, comunidades extrativistas como agregadores de valor ao produto.

\subsection{Descrição das peças publicitárias}

O corpus de análise deste trabalho é composto por três peças publicitárias de produtos da linha Ekos da Natura. Os materiais publicitários foram retirados da conta oficial da Natura na rede social Instagram, aqui é importante ressaltar que foram analisadas as fotos e suas legendas.

$\mathrm{Na}$ figura 2, há uma mulher em meio a folhagens e árvores, aparentemente nua, com olhar que demonstra certa sensualidade e encarando diretamente o espectador da imagem. Entretanto, a imagem da mulher na natureza encontra-se em segundo plano na imagem, bem como a apresentação da matéria-prima do produto (folha e semente da ucuuba), e busca-se evidenciar, em primeiro plano, os produtos em seus diversos tipos de embalagens e o logotipo "Ekos Ucuuba", ressaltando que o foco principal da peça publicitária é a divulgação do produto. A legenda destaca que o produto pretende completar a rotina de cuidados com a pele, proporcionando reparação profunda e o estímulo na produção de colágeno e elastina da pele. 


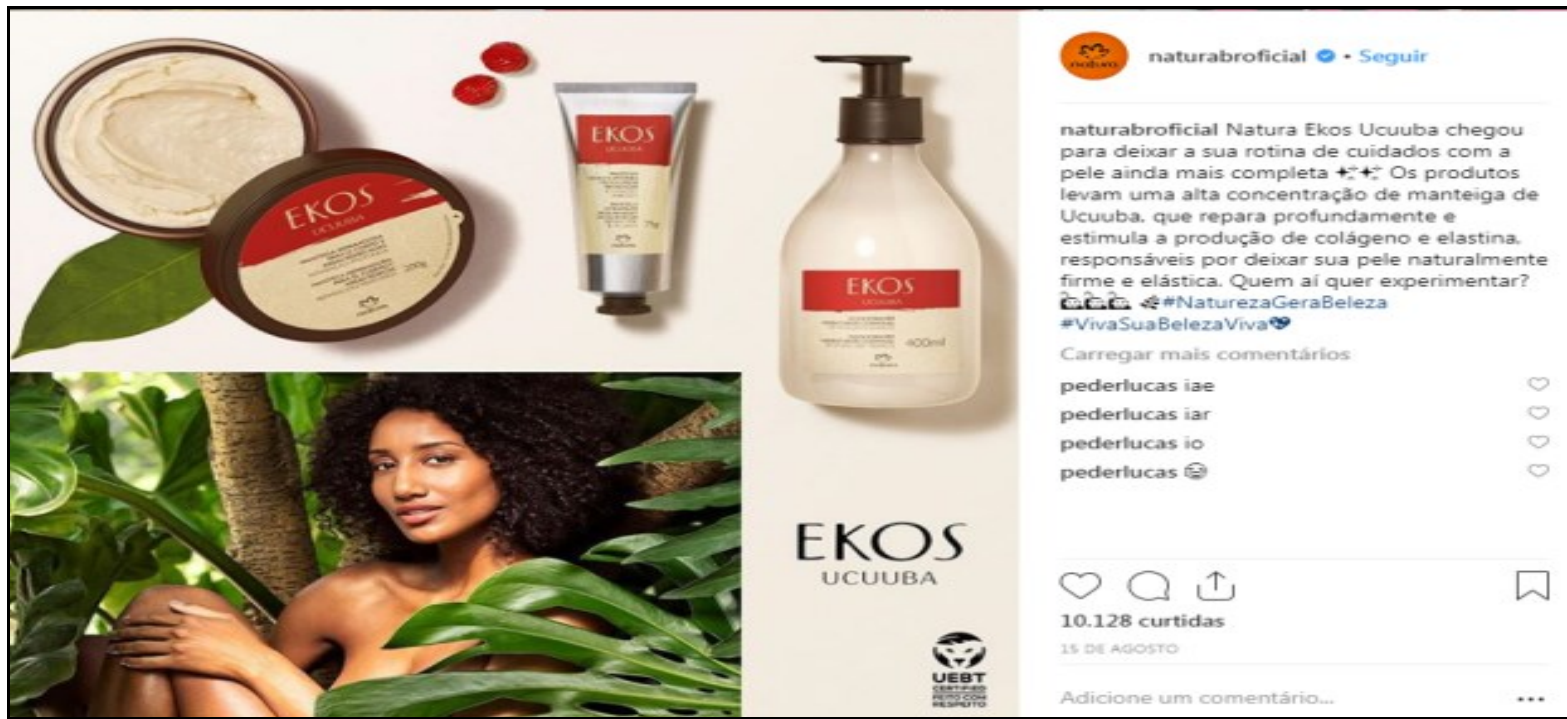

Figura 2: Peça publicitária da linha Natura Ekos Ucuuba Fonte: Instagram. Publicado em 15/08/2018. Disponível em https://www.instagram.com/p/BmgnD4olLnV/?utm_source=ig_web_copy_link

Na figura 3, há uma mulher em um cenário de natureza, com pedras e folhagens ao fundo, com roupas de aparência leve. O olhar da mulher também é direcionado ao espectador da imagem, com ar de leveza e tranquilidade, mas, ao mesmo tempo, demonstra persuasão com sutileza. Essa peça também apresenta as embalagens do produto e logotipo "Ekos Murumuru" em letras grandes e destacadas. A legenda da foto ressalta as propriedades da manteiga concentradas para a recuperação dos cabelos danificados e a qualidade dos produtos Natura.

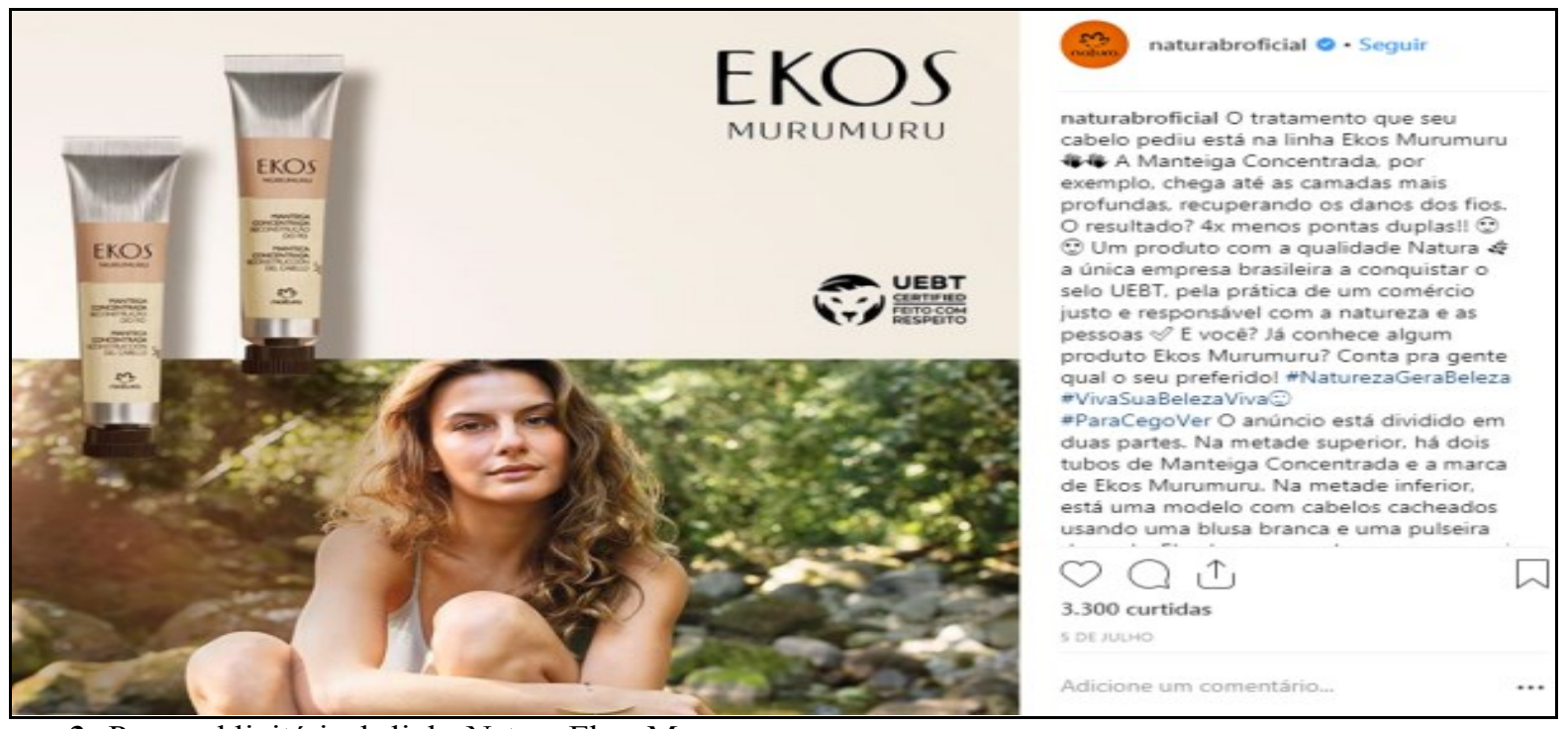

Figura 3: Peça publicitária da linha Natura Ekos Murumuru Fonte: Instagram. Publicado em 05/07/2018. Disponível em https://www.instagram.com/p/Bk2rukMF3iE/?utm_source=ig_web_copy_link

$\mathrm{Na}$ figura 4, a mulher está em meio a plantas, aparentemente nua e de costas com a face voltada para seu ombro esquerdo, os olhos estão fechados e seu semblante demonstra uma sensação de bem-estar e serenidade. Uma de suas mãos toca o braço esquerdo, de forma suave, remetendo a uma pele nutrida, bem cuidada e macia. Assim como nas peças publicitárias anteriores, a imagem da mulher encontra-se em segundo plano e a imagem do produto sobre um recipiente de madeira está em destaque, juntamente com o logotipo "Ekos Castanha". A legenda descreve a propriedade de nutrição profunda do produto, que tem textura cremosa e propicia uma pele aveludada. 
Andreina Del Carmen Camero de Lima, Eliza Pinto Narciso Saltarelli, Sabrina Soares da Silva

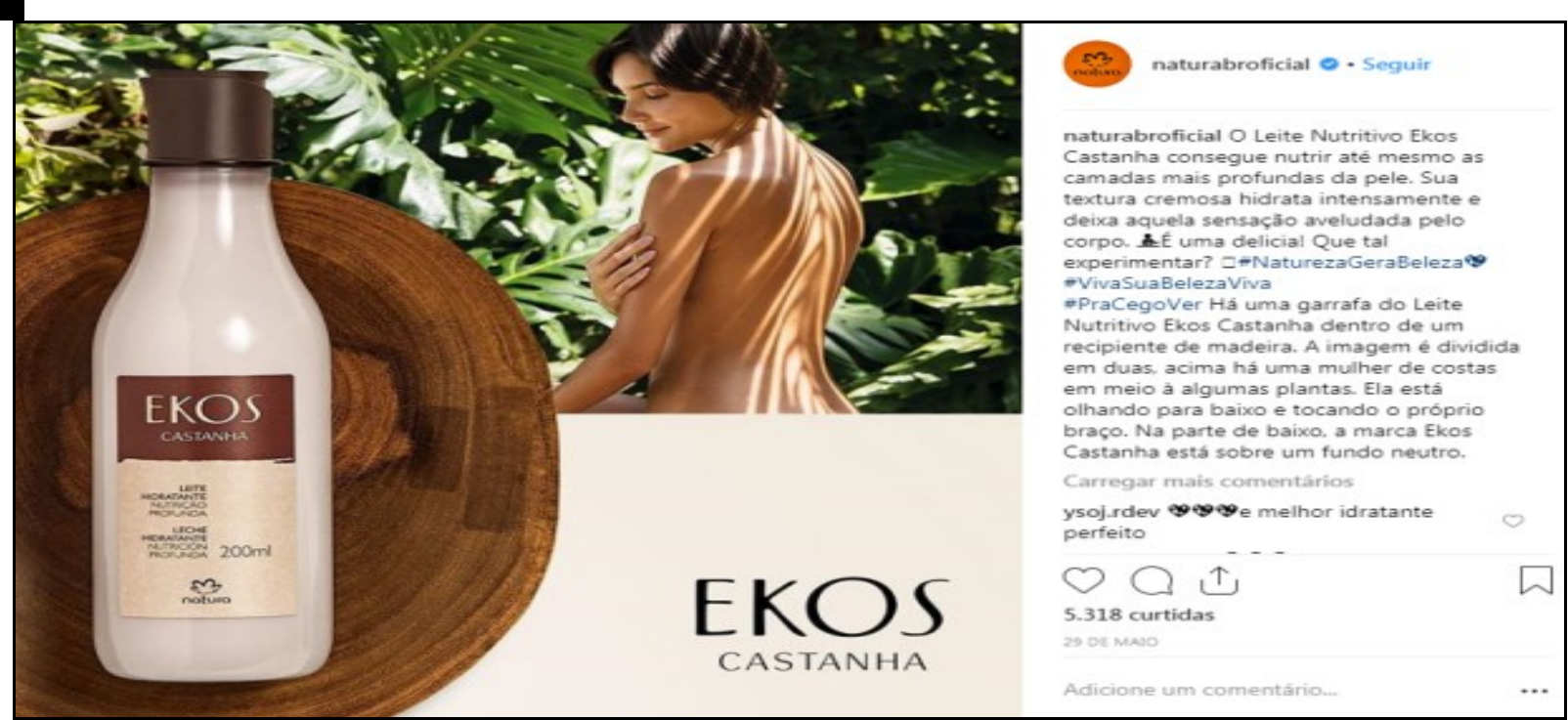

Figura 4: Peça publicitária da linha Natura Ekos Castanha

Fonte: Instagram. Publicado em 29/05/2018. Disponível em

https://www.instagram.com/p/BjXls181D3x/?utm_source=ig_web_copy_link

De modo geral, todos os anúncios publicitários apresentados remetem ao contato com a natureza, a noção de bem-estar nessa relação e a ligação entre mulher e cuidados com a beleza. Esses cenários constroem a ideia da beleza e de um contato direto com a natureza a partir do uso dos produtos da linha Natura Ekos. Inclusive o uso da expressão “\#NaturezaGeraBeleza” transmite essa percepção. Além disso, as peças publicitárias tentam imprimir uma sensação de liberdade que é propiciada no contato com o meio ambiente, ao mostrar as mulheres sempre com semblantes de serenidade e nuas.

Ao utilizar a natureza como pano de fundo das imagens e revelar o uso de matérias-primas naturais, como plantas e sementes, a Natura também busca transmitir a ideia de preocupação com o meio ambiente e o respeito à natureza. Percebe-se que os anúncios transmitem sempre uma aparência de equilíbrio, como se o recurso natural fosse parte do produto de modo harmônico e sem impactos. A demonstração desses aspectos é parte fundamental do discurso de sustentabilidade da marca Natura, principalmente na linha Ekos.

Deve destacar ainda que, as legendas apresentadas para as peças publicitárias adotam sempre uma linguagem que busca incentivar o uso do produto, mas sem fazer uso de imperativos, ou seja, buscam uma influência de modo sutil, destacando os benefícios do uso do produto e as propriedades intrínsecas dos recursos naturais utilizados como matéria-prima. Porém, o destaque dessas propriedades é sempre vinculado ao produto e não ao recurso natural em si.

Por fim, pode-se afirmar que, mesmo destacando aspectos da natureza, as peças publicitárias cumprem seu papel mercadológico de apresentar um produto, de modo a induzir seu consumo, ou seja a intenção é o consumo do produto a partir de elementos da natureza e do uso da ideia de sustentabilidade, aqui como a harmonia entre o consumidor (mulheres) e o elemento matéria-prima.

\subsection{Quem é a Natura para falar de sustentabilidade? Uma análise a partir das dimensões da colonialidade}

Após a apresentação das peças publicitárias selecionadas, serão analisados os jogos de imagens contidos nesses enunciados, a partir do primeiro jogo de imagens da proposta de Pêcheux: IA(A): Imagem do lugar de A para o sujeito colocado em A: "Quem sou eu para que eu lhe fale assim?".

Cabe frisar que se considera o sujeito: (A), como sendo a empresa Natura Cosméticos, e a imagem, IA, a ser transmitida a partir dos anúncios é a imagem que ela faz de si mesma. Ou seja, os 
enunciados pretendem destacar características e valores, de modo a persuadir o consumidor a comprar e utilizar os produtos da Linha Ekos. Esta análise está baseada no sujeito iludido - de acordo com o conceito de dupla ilusão do sujeito de Pêcheux e Fuchs (1975).

Essa constatação pode ser corroborada pelas características reforçadas e exploradas pelo sujeito no anúncio: Os produtos têm seu direcionamento voltado especialmente ao público feminino e a manutenção e o alcance da beleza física, relacionando-se, assim, com feminilidade e beleza. A utilização da natureza como caminho para a obtenção destas características é amplamente explorada, de modo a demonstrar que a utilização dos produtos proporciona completa interação e intimidade com a natureza e que esta relação está diretamente voltada para os produtos da marca. A presença da marca nas peças publicitárias está sempre relacionada às matérias-primas - castanha, ucuuba e murumuru, fazendo uma analogia entre produto e o recurso natural. A apresentação de elementos que remetem a natureza, tais como folhagens, rios, água, frutos, luz do sol, sementes, cores claras e elementos de artesanato, também são artifícios que contribuem para essa associação entre a marca e a natureza. Por fim, podemos citar o uso da logomarca do selo Uebt nos anúncios como maneira de remeter à sustentabilidade, o que também é feito ao apresentar as mulheres em uma espécie de sintonia perfeita com o que é natural. Pode-se, assim, concluir que as peças publicitárias reforçam a ideia de que a Natura é uma empresa que valoriza e utiliza a natureza de maneira sustentável e responsável, que a empresa domina os benefícios dos recursos naturais, que o uso do produto proporciona beleza, bem-estar, feminilidade, sensualidade; que os produtos são naturais, que o uso dos produtos da Natura aproxima seus consumidores da natureza e que são bons por isso.

Essas características expostas pela Natura Cosméticos são reforçadas pelo contexto em que ela está inserida; a imagem que possui no ambiente empresarial é sustentada por prêmios e títulos conquistados, além de certificações internacionais, tais como foi apontada pelo Guia Exame de Sustentabilidade 2017 como a empresa mais sustentável do Brasil; obtenção do selo "The Leaping Bunny", dado pela ONG internacional Cruelty Free que certifica empresas que não empregam qualquer tipo de teste em animais ao longo de seu processo produtivo; $14^{a}$ posição na tradicional lista "The Global 100", que relaciona as 100 empresas com as melhores práticas de sustentabilidade corporativa no mundo; e o prêmio da Organização das Nações Unidas (ONU) Campeões da Terra 2015, na categoria Visão Empresarial, para citar alguns exemplos. Essas premiações e certificações contribuem para a legitimação da imagem não só entre investidores e o mercado empresarial, mas também entre os consumidores, já que são amplamente divulgadas pela empresa.

Ainda baseada na Análise de Discurso Francesa, pode-se observar que os enunciados buscam silenciar questões a respeito da exploração da natureza, da mercantilização de recursos naturais, dos impactos ambientais do extrativismo, das exigências de padrões de beleza para as mulheres.

Sobre esses silenciamentos e as análises realizadas, acredita-se que podem estar relacionados às quatro dimensões da colonialidade: poder, ser, saber e natureza, conforme apresentado na figura 5 .

Sobre a colonialidade do poder, que é relacionada aos modos de dominação controle e subordinação que criam e contribuem para a manutenção de relações de poder, foi observado que ela está presente nas características apresentadas e nos silenciamentos dos anúncios da Natura cosméticos por reforçarem a ideia de uma exploração, comercialização e mercantilização de recursos naturais, já que mostra o uso da natureza apenas como algo benéfico, mas não evidencia que essa exploração tem como objetivo a produção de um produto e a obtenção de lucro a partir dele. Além disso, as mulheres representadas, entendidas aqui como a encarnação da empresa, encaram diretamente o receptor de maneira sedutora, induzindo ao uso (consumo) do produto, promovendo o poder sobre o indivíduo que assiste ou vê os anúncios.

No que diz respeito ao controle da subjetividade e construção da identidade que estão relacionadas à colonialidade do ser, a mesma é reproduzida no anúncio, principalmente por meio da 
imagem da mulher. Isto é evidenciado pela manutenção da ideia de que a mulher deve estar sempre em contato com a natureza para que se alcance a beleza e padrão almejados e de que a sua figura está relacionada com o natural, com o artesanal e o rústico. Outro apelo é o fato de as mulheres aparecerem nuas/seminuas em espaços da natureza, sexualizando a imagem feminina. Por fim, a evidência de que o extrativismo e a exploração são silenciados nas peças publicitárias fica por conta de a mulher ser retratada apenas como consumidora, embora muitas das comunidades extrativistas tenham como base o trabalho da mulher.

A respeito da colonialidade do saber, que controla os saberes locais e impõe o modelo de conhecimento euroamericano, está ratificada no fato de apresentar que as plantas somente se tornam benefícios legitimados quando transformadas em produtos Ekos Natura. Isso é percebido pelas legendas que remetem e explicam a planta usada como matéria-prima, criando uma intimidade com os saberes locais como se o produto pudesse levar isso até o consumidor e conciliando benefícios das plantas com os do produto. Ao fazer isso, a Natura coloniza os conhecimentos tradicionais e populares sobre o uso de plantas, ervas e recursos naturais, condicionando-os ao produto e não a natureza.

Este fato também está diretamente relacionado à colonialidade da natureza, que se refere à exploração e mercantilização de recursos e bens naturais, já que a Natura se apropria de recursos naturais como mercadorias por meio de seus produtos. A Natura apresenta que as propriedades medicinais e os benefícios das plantas pertencem aos produtos e que o contato com a natureza representado nas imagens parece real a partir do uso dos produtos, e esse contato proporciona ao consumidor beleza e bem-estar.

\begin{tabular}{|c|c|c|}
\hline Dimensão & Descrição & Representação \\
\hline Poder & $\begin{array}{c}\text { Modos de } \\
\text { Dominação, Controle } \\
\text { e Subordinação } \rightarrow \\
\text { Relações de Poder }\end{array}$ & $\begin{array}{l}\text { A exploração versus comercialização do produto. Mostra a extração como } \\
\text { algo bom, mas não deixa claro que a prática do extrativismo tem como } \\
\text { objetivo produzir um bem de consumo. } \\
\text { As mulheres aparecem iluminadas e as que estão de frente olham em uma } \\
\text { altura que encaram diretamente o receptor de maneira sedutora, induzindo ao } \\
\text { uso (consumo) do produto. }\end{array}$ \\
\hline Ser & $\begin{array}{l}\text { Controle da } \\
\text { Subjetividade e da } \\
\text { Construção da } \\
\text { Identidade }\end{array}$ & $\begin{array}{l}\text { A mulher como refém da indústria da beleza, sendo necessário estar em } \\
\text { contato com a natureza para manter sua beleza; } \\
\text { * A relação da mulher com a natureza, trabalhos artesanais e o rústico com } \\
\text { um toque delicado; } \\
\text { * As imagens das mulheres nuas/seminuas remetem à liberdade no contato } \\
\text { com a natureza e, ao mesmo tempo, à sensualidade e sexualização da mulher; } \\
\text { * As mulheres extrativistas não aparecem com os produtos, mas as } \\
\text { consumidoras são retratadas. }\end{array}$ \\
\hline Saber & $\begin{array}{l}\text { Controle dos saberes } \\
\text { locais e imposição do } \\
\text { conhecimento } \\
\text { euroamericano }\end{array}$ & $\begin{array}{l}\text { As propriedades das plantas somente são legitimadas quando se tornam } \\
\text { produtos. } \\
\text { prima, criando uma intimidade com os saberes locais como se o produto } \\
\text { pudesse levar isso até o consumidor. } \\
\text { Coloniza os conhecimentos tradicionais e populares sobre o uso de } \\
\text { plantas, ervas e recursos naturais, condicionando-os ao produto e não a } \\
\text { natureza. }\end{array}$ \\
\hline Natureza & $\begin{array}{c}\text { Exploração e } \\
\text { Mercantilização de } \\
\text { Recursos e Bens } \\
\text { Naturais }\end{array}$ & $\begin{array}{l}\text { Colonização da natureza ao se apropriar de recursos naturais como } \\
\text { mercadorias; } \\
\text { As propriedades medicinais e benefícios das plantas pertencem aos } \\
\text { produtos; } \\
\text { ideia presença das mulheres em ambientes e paisagens de natureza remete à } \\
\text { bem estar e beleza; } \\
\text { O O contato com a natureza representado nas imagens parece real a partir do } \\
\text { uso dos produtos. }\end{array}$ \\
\hline
\end{tabular}

Figura 5: Resumo das análises quanto às dimensões da colonialidade

Fonte: Elaborado pelas autoras

Revista de Gestão Social e Ambiental - RGSA, São Paulo, v. 14, n. 1, p. 18-37, jan./abr. 2020. 
Diante do exposto, evidencia-se que a perspectiva da colonialidade contribui para analisar diversos aspectos do discurso de sustentabilidade sob a lente da Análise de Discurso Francesa, corroborando com as evidências de que por de trás desse discurso de sustentabilidade ainda predominam aspectos mercantilistas e econômicos. Assim, é possível afirmar que não trata-se apenas de um texto publicitário com a intenção de vender um produto, mas um discurso carregado de sentidos que induz seu espectador a construir uma imagem da empresa relacionada a elementos específicos com a segunda intenção de agregar valor à marca a partir do que é evidenciado e do que é silenciado.

\section{CONSIDERAÇÕES FINAIS}

Este trabalho teve como objetivo analisar o discurso de sustentabilidade em peças publicitárias da Natura Cosméticos, tendo como base quatro dimensões da colonialidade, utilizando a Análise do Discurso Francesa a partir do jogo de imagens concebido por Pêcheux.

Para alcançar o objetivo proposto, foram apresentadas discussões sobre Pensamento Decolonial, Sustentabilidade e Análise do Discurso Francesa, que serviram de embasamento teórico-metodológico para o estudo.

A empresa Natura Cosméticos, especificamente a linha de produtos Ekos, foi escolhida para ter seu discurso analisado e para obter as peças publicitárias analisadas buscou-se posts do Instagram. Assim, o corpus da pesquisa ficou delimitado em três publicações na rede social do perfil oficial da Natura que tratavam de produtos da linha.

O uso de peças publicitárias, tendo como base a Análise do Discurso Francesa, permitiu que elas fossem analisadas não apenas com a finalidade de servir ao marketing e a apresentação de um produto, mas conhecer o sentido oculto presente no discurso a partir do contexto e de quem o produz. Por isso, não apenas o conteúdo do texto foi analisado, mas os sentidos produzidos a partir dele.

As peças publicitárias escolhidas foram descritas e analisadas conforme o primeiro jogo de imagens da proposta de Pêcheux: IA(A): Imagem do lugar de A para o sujeito colocado em A: "Quem sou eu para que eu lhe fale assim?".

Ao analisar o discurso de sustentabilidade de uma empresa, como a Natura, em uma perspectiva como a da Análise do Discurso Francesa combinada com a colonialidade e suas quatro dimensões (poder, ser, saber e natureza), obtém-se uma nova visão, mais ampliada e completa a respeito de como a sustentabilidade é tratada pela empresa e como tem adquirido um caráter voltado para a mercantilização e a obtenção de valores e lucros financeiros para uma organização.

Verificou-se, no trabalho realizado, que as peças publicitárias da linha Natura Ekos revelam que a empresa assume para si uma representação que beneficia sua identidade, valoriza seus conceitos básicos de sustentabilidade, reforçados pela imagem que a empresa possui na sociedade, principalmente pelo destaque na mídia, evidenciado pelas premiações e pelos títulos adquiridos que remetem a uma empresa de referência em gestão sustentável e responsabilidade socioambiental. Assim, a sustentabilidade torna-se uma incoerência, já que é utilizada pela empresa não apenas como uma finalidade, mas como um meio para se alcançar seu objetivo mercantilista e valorizar sua imagem perante o mercado, por meio da construção de uma representação.

A construção dessa representação tende a atrair consumidores que se alinhem aos valores apresentados em seus anúncios. No entanto, percebe-se que as representações criadas estabelecem imagens que não revelam todas as facetas que o uso e exploração de recursos da natureza podem promover, e que minimizam aspectos relevantes como a mulher sexualizada, o controle da subjetividade e a dominação, promovidos pelos anúncios. Evidencia-se que o excesso de se dizer sustentável e de enaltecer sua relação com a natureza é um modo de evitar esses outros sentidos que poderiam surgir, e, que são desta maneira, silenciados.

Ressalta-se que, apesar da limitação do corpus, as análises podem revelar traços importantes do discurso da empresa sobre o conceito de sustentabilidade, trazendo insights que podem 
contribuir para a análise de outras peças publicitárias e até mesmo os discursos de outras empresas. Com base nessa iniciativa, acredita-se que seria pertinente que outros discursos institucionais, campanhas publicitárias e relatórios de sustentabilidade fossem analisados, inclusive com recortes temporais para que fosse possível uma análise comparativa ao longo dos anos.

A intenção do trabalho não é minimizar os avanços em gestão ambiental e sustentável, mas sim demonstrar que esses avanços são utilizados como artifícios para promover a imagem empresarial e os ganhos financeiros, bem como maior adesão aos produtos da marca.

\section{REFERÊNCIAS}

Abemd (2020) Associação Brasileira de Marketing de Dados. Disponível em: https://abemd.org.br/ Acesso em 14 de abril de 2020 .

Alcazar, M. R., Spers, R. G.\& Arida, R. M. (2007). Internacionalização da natura na França: estratégias e posicionamento de marketing para um mercado sofisticado. Revista Eletrônica de Negócios Internacionais, 2(2), 221-246.

Amazonas, M. D. C. (2002). Desenvolvimento sustentável e teoria econômica: o debate conceitual nas perspectivas neoclássica, institucionalista e da economia ecológica. In: Nobre, M. \& Amazonas, M. C. Desenvolvimento sustentável: a institucionalização de um conceito. Brasília: Edições Ibama. cap. 1, 107-286.

Anderson, E. (2014). Coloniality and multinational mining companies: a relationship of reciprocity in postcolonial Societies. American University. Recuperado em 15 fev.2018, de:

https://auislandora.wrlc.org/islandora/object/auislandora\%3 A11376.

Araújo, E. R. \& Fernandes, F. R. C. (2016). Mineração no Brasil: crescimento econômico e conflitos ambientais. Cetem/Mcti. Recuperado em 24 março 2018, de:

http://mineralis.cetem.gov.br/bitstream/cetem/1909/1/conflitos_ambientais_cap.2\%20p65.pdf.

Ashar, M. (2015). Decolonizing what? Categories, concepts and the enduring 'not yet'. Cultural Dynamics, 27(2), 253-265.

Assis, W. F. T. (2008). Conflitos ambientais na produção de agrocombustíveis: colonialidade da natureza e manutenção da economia capitalista. In Encontro Nacional da Associação Nacional de Pós-Graduação e Pesquisa em Ambiente e Sociedade-4 -Enanppas, Brasília.

Assis, W. F. T. (2014). Do colonialismo à colonialidade: expropriação territorial na periferia do capitalismo. Caderno $\mathrm{CRH}, 27(72)$.

Ballestrin, L. M. A. (2013). América Latina e o giro decolonial. Revista Brasileira de Ciência Política, 2(11), 89-117.

Ballestrin, L. M. A. (2015). Colonialidade e Democracia. Revista Estudos Políticos, 5, 191-209.

Ballestrin, L. M. A. (2017). Modernidade/colonialidade sem "imperialidade"? O elo perdido do giro decolonial. Dados, 60(2), 505-540.

Barbieri, J. C. (2007). Gestão ambiental empresarial: conceitos, modelos e instrumentos. 2. ed. São Paulo: Saraiva, 382.

Barnett, J. (2001). The meaning of environmental security. London: Zed Books, 192 p.

Becker, B. (1997). Sustainability assessment: a review of values, concepts, and methodological approaches. Washington: Consultative Group on International Agricultural Research, 63.

Bernardino-Costa, J.\& Grosfoguel, R. (2016). Decolonialidade e perspectiva negra. Sociedade e Estado, 31(1), 15-24.

Boff, L. (2010). O pecado maior do capitalismo: o risco do ecocídio e do biocídio. Recuperado em nov.2010. de: http://www. leonardoboff. com/site/lboff. htm>.

Cabette, E. L. S. (2007). É sustentável a tese do desenvolvimento sustentável. Âmbito Jurídico. Rio Grande (45). 
Carrieri, A. P. (2003). O meio ambiente: discurso consistente ou prática vazia? Uma reflexão sobre os discursos ambientais, a teoria organizacional e o caso brasileiro. Revista de Administração Pública, 37(6), 1209-1231.

Carvalho, M. C. A. (2012). A reconfiguração das relações de poder na América Latina: recolonização e resistèncias em um contexto neoliberal. Revista Electrónica de Geografía y Ciencias Sociales. 16, 418 (61).

Carvalho, P. D. (2015). Há lugar para movimentos sociais na teoria decolonial? In Congreso Latinoamericano de Ciencia Política (Alacip), 8. Pontificia Universidad Católica del Perú, Lima.

Cavalcanti, C. (1998). Sustentabilidade da economia: paradigmas alternativos de realização econômica. In: Cavalcanti, C. (Org.). Desenvolvimento e natureza: estudos para uma sociedade sustentável. 2. ed. São Paulo: Cortez, cap. 9, 153-174.

Chizzotti, A. (2010). Pesquisa qualitativa em ciências humanas e sociais. (3. ed.) Petropolis: Vozes. Clemente, G. \& Melo, C. (2015). A identidade visual como uma ferramenta de fidelização com o consumidor. estudo de caso: Natura Cosméticos. Anais do Congresso de Ciências da Comunicação na Região Nordeste - Natal - RN, 17.

Coelho, A. L. A. L., Coelho, C.\& Godoi, C. K. (2013). O discurso da sustentabilidade e sua inserção no contexto organizacional. Revista Gestão \& Conexões, 2(1), 147-186.

Coelho, A. L. A. L.\& Godoi, C. K. (2010). Coerência entre o discurso institucional e o discurso midiático sobre a sustentabilidade. Revista de Gestão Social e Ambiental, 4(3), 70-89.

Coradin, C. (2017). Desenvolvimento, alternativas de/ao desenvolvimento e a questão ambiental. RELACult - Revista Latino-Americana de Estudos em Cultura e Sociedade, 3.

Escobar, A. (2005). O lugar da natureza e a natureza do lugar: globalização ou pós-desenvolvimento. p. 133168. In Lander, E. (Org.). (2005). A colonialidade do saber: eurocentrismo e ciências sociais. Perspectivas latino-americanas. Buenos Aires: Clacso.

Espanhol, C. O. (2017). O pensamento decolonial como perspectiva contra-hegemônica nos debates teóricos das relações internacionais. Encontro da Abri - Perspectivas sobre o poder em um mundo em redefinição, 6 . Belo Horizonte.

Esteva, G. (1999). The zapatista's and people's power. Capital and Class, London, 68, 46-85.

Exame (2018). As 100 empresas mais sustentáveis do mundo em 2018. Recuperado em nov.2018, de: https://exame.abril.com.br/negocios/as-100-empresas-mais-sustentaveis-do-mundo-em-2018/.

Fairclough, N. (2001). Critical discourse analysis as a method in social scientific research. Methods of critical discourse analysis, 5, 121-138.

Figueiredo, G. N., Abreu, R. L., \& Las Casas, A. L. (2009). Reflexos do índice de sustentabilidade empresarial (ISE) na imagem das empresas: uma análise do consumidor consciente e do marketing ambiental. Pensamento \& Realidade, 24(1), 107-128.

Gonçalves, A. T.P. (2016). Análise de conteúdo, análise do discurso e análise de conversação: estudo preliminar sobre diferenças conceituais e teórico-metodológicas. Administração: Ensino e Pesquisa, 17(2), 275.

Hays, J. M., Pereseina, V., Alshuaibi, A. S. I., \& Saha, J. (2020). Lessons in sustainable process paradigm. a case study from Dubai. The International Journal of Management Education, 18(1), 100366.

Hernandez, A. C. \& Rabinovici, A. (2015). Influência das ações socioambientais da empresa Natura sobre suas consultoras em Sorocaba (SP). Revista Brasileira de Educação Ambiental (RevBEA), 10(2), 36-57.

Hoffman, A. J. (1999). Institutional evolution and change: Environmentalism and the US chemical industry. Academy of Management Journal, 42(4), 351-371.

Langhelle, O. (2000). Sustainable development and social justice: expanding the Rawlsian framework of global justice. Environmental Values, Isle of Harris, 9(3), 295-323. 
Leite, M. M. C. (2017). Fotografias de uma infância nos jornais: dois valores possíveis. Anais do Seminário Interno de Pesquisas do Laboratório Arquivos do Sujeito, (4), 73-79.

Lins, L. D. S., \& Silva, R. N. S. (2009). Responsabilidade Socioambiental ou Greenwash: uma avaliação com base nos relatórios de sustentabilidade ambiental. Sociedade, Contabilidade e Gestão, 4(1), 91-105.

Martinez-Alier, J. (1992). De la economía ecológica al ecologismo popular. Montevideo: Icaria, 231.

Mason, M. (1999). Environmental democracy. London: Earthscan, 266.

Merino Acuña, R. (2015). The politics of indigenous self-determination: extractive industries, state policies and territorial rights in the Peruvian Amazon. Tese de Doutorado. University of Bath.

Mignolo, W. D. (2007). 'Epistemic Disobedience': the de-colonial option and the meaning of identity in politics. Gragoatá, 12(22).

Mignolo, W. D. (2011). Epistemic disobedience and the decolonial option: A manifesto. Transmodernity, $1(2), 3-23$.

Mussalim, F. (2018) A dimensão discursiva da cognição ou a dimensão cognitiva do discurso. Cadernos de Estudos Lingüísticos, 60(2), 400-413.

Mussalin, F. (2001). Análise do Discurso. In Mussalin, F.\& Bentes, A. C. Introdução à linguísticadomínios e fronteiras. Ed. São Paulo: Cortez, 2(2), 101-142.

Natura. (2018). Nossa história. Recuperado em nov.2018, de://www.natura.com.br/a-natura/nossa-historia.

Oliveira, C. K. (2016). Breve introdução ao giro decolonial: poder, saber e ser. Anais do Seminário Cientifico da Facig (2).

Orlandi, E. P. (2005). Michel Pêcheux e a análise de discurso. Estudos da Língua (gem), 1, 9-13.

Pêcheux, M. (1990). Delimitações, inversões, deslocamentos. Cadernos de estudos linguísticos, 19, 7-24.

Pêcheux, M. (1969). Análise de conteúdo e teoria do discurso. Por uma análise automática do discurso: uma introdução à obra de Michel Pêcheux, 3, 79-87.

Pêcheux, M. \& Fuchs, C. (1975). Mises au point et perspectives à propos de l'analyse automatique du discours. Langages, (37), 7-80.

Pinto, L. B., Lima, A. D. C. C., Lobato, C. B. P.\& Villarta-Neder, M. A. (2014). O jogo de imagens no discurso das propagandas de processos seletivos bancários: do que você é feito? Revista FSA, 11(3).

Pires, F. M.\& Fischer, A. L. (2014). Integração entre gestão de pessoas e estratégia de sustentabilidade: o caso Natura. Revista de Gestão Social e Ambiental, 8(1), 54.

Quijano, A. (2005). Colonialidade do poder, eurocentrismo e América Latina. P.107-130. In Lander, E. (Ed.). (2005). A colonialidade do saber: eurocentrismo e ciências sociais. Perspectivas latino-americanas. Buenos Aires: Clacso.

Quijano, A. \& Wallerstein, I. (1992). 'Americanity' as a Concept, or the Americas in the Modern World. International social science journal, 44(4), 549-557.

Redclift, M. (2005). Sustainable development (1987-2005): an oxymoron comes of age. Sustainable Development, Brussels, 13(4), 212-227.

Redclift, M. (1994). Sustainable development: economics and the environment. In: Redclift, M. \& Sage, C. (eds.) Strategies for Sustainable Development: Local Agendas for the Southern Hemisphere, Chichester: J. Wiley, chap. 2,17-34.

Reinhardt, F. L. (1999). Bringing the environment down to earth. Harvard Business Review, 77, (4), 149149.

Rocha, D. \& Deusdará, B. (2005). Análise de conteúdo e análise do discurso: aproximações e afastamentos na (re) construção de uma trajetória. Alea: Estudos Neolatinos, 7(2), 305-322.

Ruiz Ruiz, J. (2009). Análisis sociológico del discurso: métodos y lógicas. Forum Qualitative Sozialforschung. 
Sachs, I. (2005). Prefácio. In: Veiga, J. E. Desenvolvimento sustentável: o desafio do século XXI. Rio de Janeiro: Garamond, 9-11.

Sachs, I. (2004). Desenvolvimento includente, sustentável e sustentado. Rio de Janeiro: Garamond, 251 p.

Santos, F. (2014). Sustentabilidade ambiental na propaganda: das imagens aos mitos na comunicação persuasiva. Dissertação de Mestrado. UFRGS - Universidade Federal do Rio Grande do Sul.

Silva, A. P. S. (2011a). Comunicação organizacional em tempo de redes sociais: Natura no facebook. Dissertação de Mestrado. Unesp - Universidade Estadual Paulista.

Silva, A. R.\& Baptista, D. M. (2015). Abordagens de análise de discurso na ciência da informação: panorama dos estudos brasileiros. Informação \& Sociedade: Estudos, 25(2), 103.

Silva, M. A. S. (2005). Sobre a Análise do Discurso. Revista de Psicologia da Unesp, 4(1), 25-25.

Silva, M. D. M., Simonian, L. T. L., \& Amaral Filho, O. (2013). A publicidade e a definição de regras quanto ao uso do conceito de sustentabilidade. Razón y palabra, 18(85).

Silva, S. S. (2011b). Paradigmas ambientais e sustentabilidade: o que evidenciam alguns discursos organizacionais. Tese de Doutorado. Ufla - Universidade Federal de Lavras.

Silva, S. S., Reis, R. P.\& Amâncio, R. (2014). Conceitos atribuídos à sustentabilidade em organizações de diferentes setores. Revista de Ciências da Administração, 90-103.

Silva, S. S., Reis, R. P.\& Amâncio, R. (2011). Paradigmas ambientais nos relatos de sustentabilidade de organizações do setor de energia elétrica. Revista de Administração Mackenzie, 12(3).

Ugarte, M. (2014). Ethics, discourse, or rights? A discussion about a decolonizing project in planning. Journal of Planning Literature, 29(4), 403-414.

Vasconcelos, I. F. G.\& Vasconcelos, F. C. (2003). Identidade, legitimação social e teoria organizacional: contribuições de uma análise sociológica da política de gestão de pessoas da Natura. Organizações \& Sociedade, 10 (27), 41-59.

Villarta-Neder, M.A. (2004). Silêncio da memória x Memória do silêncio: uma parábola sobre efeitos de sentido. Uberlândia: Edufu, 133 - 154.

\footnotetext{
${ }^{i}$ A União para BioComércio Ético (UEBT- na sigla em inglês) é uma associação sem fins lucrativos que promove o abastecimento com respeito. Apoiamos e verificamos os compromissos das empresas com a inovação e o fornecimento que contribuem para um mundo no qual as pessoas e a biodiversidade prosperam.(https://www.ethicalbiotrade.org/about-uebt/).
} 